\title{
HUBUNGAN PENGETAHUAN DAN SIKAP PEREMPUAN HAMIL DENGAN PEMBERIAN IMUNISASI TETANUS TOXOID (TT) DI PUSKESMAS SUNGAI PANAS KOTA BATAM, 2019
}

\author{
THE RELATIONSHIP BETWEEN KNOWLEDGE AND ATTITUDES OF \\ PREGNANT WOMEN WITH THE GIVING OF TETANUSS TOXOID (TT) \\ IMMUNIZATION AT THE PUBLIC HEALTH CENTER OF SUNGAI PANAS, \\ BATAM CITY, 2019
}

\author{
Mariyana $^{1}$, Sarmauli Franshisca Sihombing ${ }^{2}$ \\ Prodi Kebidanan, Fakultas Kedokteran, Universitas Batam \\ mariyana@univbatam.ac.id
}

\begin{abstract}
ABSTRAK : Imunisasi Tetanus Toxoid (TT) merupakan pembentukan kekebalan tubuh untuk mencegah penyakit yang dapat menyebabkan kematian pada ibu dan janin. Imunisasi Tetanus Toxoid bertujuan untuk mencegah penyakit tetanus yang dapat menyerang semua orang, terutama ibu dalam proses persalinan dan nifas akibat terkontamisasi oleh kuman tetanus. Data dari World Health Organization (WHO) menghitung insidensi secara global kejadian tetanus di dunia secara kasar berkisar antara 0,5 - 1 juta kasus dan Tetanus Neonatorum (TN) terhitung sekitar 50\% dari kematian akibat tetanus di negara - negara berkembang. Perkiraan insidensi tetanus secara global adalah 18 per 100.000 populasi per tahun.Tujuan umum penelitian Diketahui hubungan antara pengetahuan dan sikap ibu hamil dengan pemberian imunisasi Tetanus Toxoid (TT) di UPT Puskesmas Sungai Panas Kecamatan Bengkong Kota Batam tahun 2019.penelitian ini bersifat cross sectional, tempat penelitian di UPT. Puskesmas Sungai Panas Tahun 2019, Populasi penelitian adalah ibu hamil Trimester II dan Trimester III yang berjumlah 115 orang yang berkunjung ke Puskesmas Sungai Panas. Pengambilan sampel degan teknikrandom sampling, jumlah sampel 53 responden, Instrumen mengunakan kuesioner yang berisikan 15 pernyataan terkait pengetahuan dan sikap tentang imunisasi tetanus toxoid, uji Analisa yang digunakan yaitu analisa chi-square.Hasil univariat yakni dari sebanyak 53 responden dan diperoleh hasil, untuk pengetahuan baik sebanyak 31 orang $(58.5 \%)$ dan pengetahuan kurang baik sebanyak 22 orang (41.5\%) dan untuk sikap baik sebanyak 35 orang (66.0\%) dan sikap buruk sebanyak 18 orang (34.0\%). Hasil Bivariatterdapat hubungan antara pengetahuan ibu hamil dengan pemberian imunisasi tetanus toxoid dengan analisis chi-square P-value 0.029 , dan ada hubungan antara sikap ibu hamil dengan pemberian imunisasi tetanus toxoid dengan analisis chi-square P-value 0.008. Kesimpulan ada hubungan antara Pengetahuan dan Sikap Ibu Hamil Dengan Pemberian Imunisasi Tetanus Toxoid Di Puskesmas Sungai Panas Kota Batam Tahun 2019. Saran bagi UPT. Puskesmas Sungai Panas Diharapkan dapat lebih meningkatkan promosi dan penyuluhan kesehatan bagi ibu hamil tentang pentingnya imunisasi tetanus toxoid (TT).Sehingga masyarakat khususnya ibu hamil mengetahui pentingnya imunisasi tetanus toxoid (TT) dan mendapatkan pelayanan imunisasi Tetanus Toxoid secara lengkap.
\end{abstract}

Kata kunci :Pengetahuan, Sikap, Pemberian Imunisasi Tetanus Toxoid (TT).

ABSTRACT : Tetanus Toxoid (TT) immunization is the body's emergency message to prevent diseases that can cause death to the mother and fetus. Tetanus Toxoid immunization aims to prevent tetanus, which can affect everyone, especially mothers in labor and childbirth due to being contaminated by tetanus germs. Data from the World Health Organization (WHO) calculates the global incidence of tetanus in the world which ranges from roughly $0.5-1$ million cases and Tetanus Neonatorum (TN) accounts for about 50\% of tetanus deaths in developing countries. The estimated global incidence of tetanus is 18 per 100,000 population per year. The general objective of the study is to know the relationship between the knowledge and attitudes of pregnant women 
with the administration of Tetanus Toxoid (TT) Immunization in the technical implementation unit of the Sungai Panas Public health center, Bengkong district, Batam city in 2019. This research is cross sectional, the research place is in UPT. Public Health Center of Sungai Panas in 2019, the research population of pregnant women in Trimester II and Trimester III which stated that 115 people visited Public Health Center of Sungai Panas. Sampling with random sampling technique, total sample of 53 respondents, the instrument used was a questionnaire containing 15 statements related to knowledge and attitudes about tetanus toxoid immunization, the analysis test used chisquare analysis. Univariate results, namely from 53 respondents and obtained results, for good knowledge as many as 31 people (58.5\%) and poor knowledge as many as 22 people (41.5\%) and for good attitudes as many as 35 people (66.0\%) and bad attitude of 18 people (34.0\%). Bivariate results showed a relationship between the knowledge of pregnant women with tetanus toxoid immunization with a chi-square P-value analysis of 0.029, and there was a relationship between the attitudes of pregnant women and giving tetanus toxoid immunization with a chi-square P-value analysis of 0.008. The conclusion is that there is a relationship between Knowledge and Attitudes of Pregnant Women and Giving Tetanus Toxoid Immunization at the Public Health Center of Sungai Panas, Batam City in 2019. Suggestions for UPT. Public Health Center of Sungai Panas is expected to increase health promotion and education for pregnant women about the importance of tetanus toxoid (TT) immunization. So that people, especially pregnant women, see the importance of tetanus toxoid (TT) immunization and get complete Tetanus Toxoid immunization services.

Key words: Knowledge, Attitude, Tetanus Toxoid (TT) Immunization.

\section{A. PENDAHULUAN}

Imunisasi Tetanus Toxoid (TT) merupakan pembentukan kekebalan tubuh untuk mencegah penyakit yang dapat menyebabkan kematian pada ibu dan janin. Data dari WHO menghitung insidensi secara global kejadian tetanus di dunia secara kasar berkisar antara 0,5 - 1 juta kasus dan Tetanus Neonatorum (TN) terhitung sekitar 50\% dari kematian akibat tetanus di negara - negara berkembang. Perkiraan insidensi tetanus secara global adalah 18 per 100.000 populasi per tahun.

Dikota Batam sendiri cakupan kelengkapan imunisasi Tetanus Toksoid selama tahun 2019 belumlah mencapai target yang ditetapkan. Pencapaian kelengkapan imunisasi TT2 pada Ibu Hamil sampai dengan bulan Desember 2019 untuk kota Batam hanya 13,5 (4.270 dari 31.620 sasaran bumil).

Menurut Dinas Kesehatan Kota Batam Tahun (2018), Pemberian Imunisasi Tetanus Toxoid bertujuan untuk mencegah penyakit tetanus yang dapat menyerang semua orang, terutama ibu dalam proses persalinan dan nifas akibat terkontaminasi oleh kuman tetanus. Ibu hamil harus mendapatkan penjelasan tentang pentingnya imunisasi TT sebanyak 5 kali seumur hidup. Setiap ibu hamil yang belum pernah imunisasi TT harus mendapatkan imunisasi TT paling sedikit 2 kali suntikan dengan dosis $0,5 \mathrm{cc}$ disuntikkan secara intramuskuler atau subkutan.

Efek samping dari imunisasi Tetanus Toxoid (TT) biasanya hanya gejala ringan saja seperti kemerahan, pembengkakan dan rasa nyeri pada tempat suntikan. Menurut Notoadmojo dalam Yusriani (2018), Pengetahuan adalah merupakan hasil dari tahu, dan ini terjadi setelah orang dan melakukan penginderaan terhadap suatu objek tertentu.Pendidikan ibu berpengaruh pada sikap dan perilaku dalam mengakses informasi yang terkait dalam pemeliharaan dan peningkatan kesehatan ibu. Menurut Notoadmojo dalam Yusriani (2018), Sikap adalah suatu bentuk evaluasi atau reaksi perasaan, sikap seseorang terhadap suatu objek adalah perasaan mendukung atau memihak pada objek tersebut.Sikap sebagai efek positif atau efek negatif terhadap objek psikologis.

\section{Tujuan Umum}

Diketahui Hubungan antara pengetahuan dan sikap ibu hamil dengan pemberian imunisasi Tetanus Toxoid (TT) di UPT Puskesmas Sungai Panas Kecamatan Bengkong Kota Batam tahun 2019. 


\section{B. METODELOGI PENELITIAN}

Penelitian ini termasuk jenis penelitian Analitik.dimana peneliti bermaksud untuk mengetahui bagaimana dan mengapa suatu fenomena terjadi melalui sebuah analisis statistik seperti korelasi antara sebab dan akibat atau faktor risiko.Didalam penelitian ini Peneliti menggunakan Cross Sectional, dimana pengumpulan data dilakukan bersamaan secara serentak dalam satu waktu (Masturoh dkk,2018).

\section{HASIL PENELITIAN}

\section{A. Analisa Univariat}

Table 4.3

Distribusi Frekuensi Responden Berdasarkan Tingkat Pengetahuan Tentang Imunisasi TT Di UPT Puskesmas Sungai Panas Kota Batam Tahun 2019.

\begin{tabular}{cccc}
\hline No. & Pengetahuan & N & Persentase (\%) \\
\hline 1 & Baik & 31 & 58.5 \\
2 & Kurang Baik & 22 & 41.5 \\
\hline & Total & 53 & 100
\end{tabular}

Berdasarkan hasil tabel 4.3 dapat dijelaskan jumlah responden sebanyak 53 responden dan diperoleh hasil, untuk pengetahuan baik sebanyak 31 orang (58.5\%) dan pengetahuan kurang baik sebanyak 22 orang $(41.5 \%)$.

Tabel 4.4

Distribusi Frekuensi Responden Berdasarkan Sikap Tentang Imunisasi TT Di UPT Puskesmas Sungai Panas Kota Batam

Tahun 2019.

\begin{tabular}{lccc}
\hline No. & Sikap & N & Persentase (\%) \\
\hline 1 & Baik & 35 & 66.0 \\
2 & Buruk & 18 & 34.0 \\
\hline & Total & 53 & 100 \\
\hline
\end{tabular}

Berdasarkan hasil tabel 4.4 dapat dijelaskan jumlah responden sebanyak 53 responden dan diperoleh hasil, untuk sikap baik sebanyak 35 orang (66.0\%) dan sikap buruk sebanyak 18 orang $(34.0 \%)$.

Tabel 4.5

Distribusi Frekuensi Responden Berdasarkan Pemberian Imunisasi TT Di Puskesmas Sungai Panas Kota Batam

Tahun 2019.

\begin{tabular}{cccc}
\hline No. & Pemberian & N & Persentase (\%) \\
\hline 1 & Diberikan & 29 & 54.7 \\
2 & Tidak Diberikan & 24 & 45.3 \\
\hline & Total & 53 & 100 \\
\hline
\end{tabular}

Berdasarkan hasil tabel 4.5 dapat dijelaskan jumlah responden sebanyak 53 responden dan diperoleh hasil, diberikan imunisasi TT sebanyak 29 orang (54.7\%), dan tidak diberikan sebanyak 24 orang $(45.3 \%)$. 


\section{B. Analisa Bivariat}

Tabel 4.6

Hubungan Pengetahuan Ibu Hamil Dengan Pemberian Imunisasi Tetanus Toxoid Di

Puskesmas Sungai Panas

Kota Batam Tahun 2019.

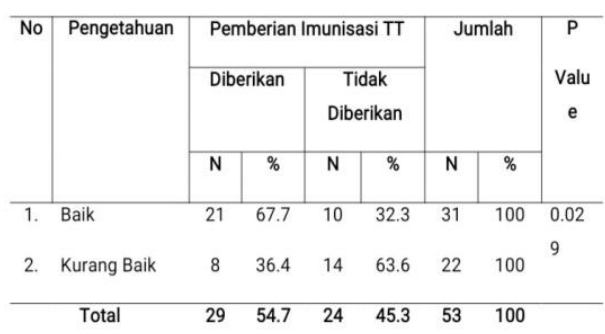

Hasil tabel4.6 dapat dilihat jumlah responden sebanyak 53 orang. Hasil yang diperoleh menunjukkan sebanyak 31 responden dengan pengetahuan baik, 21 responden $(67,7 \%)$ diberikan imunisasi tetanus toxoid dan 10 responden $(32,3 \%)$ tidak diberikan imunisasi tetanus toxoid. Sedangkan pada responden yang memiliki pengetahuan kurang yaitu sebanyak 22 responden, 8 responden $(36.4 \%)$ diberikan imunisasi tetanus toxoid dan 14 responden $(18,2 \%)$ tidak diberikan imunisasi tetanus toxoid.

Hasil uji statistik dengan Chi-Square diperoleh nilai $p$ value $=0,029 \quad(<\quad 0,05)$ dapatdisimpulkanbahwaHo ditolak, artinya ada hubungan antara pengetahuan ibu hamil dengan pemberian imunisasi tetanus toxoid di Puskesmas Sungai Panas Kota Batam Tahun 2019.

Tabel 4.7

\section{Hubungan Sikap Ibu Hamil Dengan Pemberian Imunisasi Tetanus Toxoid Di Puskesmas Sungai Panas Kota Batam} Tahun 2019.

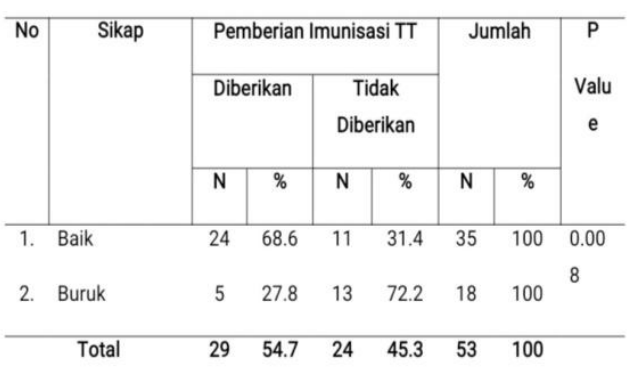

Hasil tabel4.7 dapat dilihat jumlah responden sebanyak 53 orang. Hasil yang diperoleh menunjukkan sebanyak 35 responden dengan sikap baik, 24 responden $(68,6 \%)$ diberikan imunisasi tetanus toxoid dan 11 responden $(31,4 \%)$ tidak diberikan imunisasi tetanus toxoid. Sedangkan pada responden yang memiliki sikap buruk yaitu sebanyak 18 responden, 5 responden (27.8\%) diberikan imunisasi tetanus toxoid dan 13 responden (72.2\%) tidak diberikan imunisasi tetanus toxoid.

Hasil uji statistik dengan Chi-Square diperoleh nilai $p$ value $=0,008 \quad(<\quad 0,05)$ dapatdisimpulkanbahwaHo ditolak, artinya ada hubungan antara sikap ibu hamil dengan pemberian imunisasi tetanus toxoid di Puskesmas Sungai Panas Kota Batam Tahun 2019. 


\section{PEMBAHASAN}

\section{A. Analisa Univariat}

a. Pengetahuan

Ibu hamil yang memiliki pengetahuan kurang baik dikarenakan ibu tidak mengetahui kapan jadwal dan jarak pemberian imunisasi Tetanus Toxoid.

Menurut Notoadmojo dalam Yusriani (2018), Pengetahuan adalah merupakan hasil dari tahu, dan ini terjadi setelah orang dan melakukan penginderaan terhadap suatu objek tertentu.Pengetahuan yang dimiliki seseorang dapat merupakan motivasi untuk bersikap dan melakukan suatu tindakan bagi orang tersebut (Yusriani dkk,2018).

Asumsi peneliti, pengetahuan ibu kurang baik dikarenakan berpengaruh dengan pendidikan ibu.Karena pendidikan juga merupakan faktor yang mempengaruhi presepsi seseorang untuk menerima informasi yang semakin baik.

b. Sikap

Menurut Notoatmodjo yang dikutip dalam (Yusriani \& Alwi, 2018), Sikap adalah suatu bentuk evaluasif atau reaksi perasaan, sikap seseorang terhadap suatu objek adalah perasaan mendukung atau memihak pada objek tersebut.

Asumsi peneliti, sikap merupakan kesediaan untuk bertindak.Dengan adanya sikap baik seorang ibu hamil, merupakan suatu peranan penting bagi ibu hamil untuk mau melakukan imunisasi Tetanus Toxoid (TT).

c. Pemberian

Imunisasi Tetanus Toksoid (TT) merupakan pembentukan kekebalan tubuh untuk mencegah penyakit yang dapat menyebabkan kematian pada ibu dan janin (Sulistyawati, 2011).Pemberian Imunisasi Tetanus Toxoid bertujuan untuk mencegah penyakit tetanus yang dapat menyerang semua orang, terutama ibu dalam proses persalinan dan nifas akibat terkontaminasi oleh kuman tetanus.

asumsi peneliti, ibu hamil yang tidak mendapatkan atau diberikan imunisasi Tetanus Toxoid dikarenakan pengetahuan ibu yang kurang tentang imunisasi TT seperti ibu tidak mengetahui jadwal imunisasi TT, dan kenapa harus dilakukan imunisasi TT.

\section{B. Analisa Bivariat}

a. Hubungan Pengetahuan Dengan Pemberian Imunisasi TT

Menurut Yusriani, dkk (2018) bahwa pengetahuan merupakan hasil dari tahu, dan ini terjadi setelah orang dan melakukan penginderaan terhadap suatu objek tertentu. Penginderaan itu terjadi melalui panca indera manusia, yakni indra penglihatan, pendengaran, penciuman, rasa dan raba. Sebagian besar pengetahuan manusia diperoleh melalui mata dan telinga.Pengetahuan ibu hamil tentang imunisasi TT juga berkaitan erat dengan kepatuhan dalam melakukan imunisasi TT.

asumsi peneliti bahwa ada hubungan antara pengetahuan dengan pemberian imunisasi tetanus toxoid (TT). Ibu hamil yang memiliki pengetahuan baik tetapi tidak melakukan atau belum mendapatkan imunisasi tetanus toxoid (TT), berdasarkan hasil wawancara yang dilakukan selama penelitian didapatkan hasil ibu yang tidak melakukan imunisasi dikarenakan ada beberapa faktor pendukung seperti pengalaman sebelumnya dimana pada kehamilan anak pertama ibu tidak melakukan imunisasi TT dan anak nya lahir dengan keadaan sehat dan selamat, jadi untuk kehamilan anak kedua ibu juga tidak mau melakukan pemberian imunisasi tetanus toxoid (TT) selain itu kepercayaan juga menjadi faktor pendukung kenapa ibu tidak mau melakukan pemberian imunisasi tetanus toxoid (TT). Sedangkan ibu hamil yang pengetahuan nya kurang baik tetapi mendapatkan imunisasi 
tetanus toxoid (TT) dikarenakan sikap ibu yang baik sehingga ibu mau untuk melakukan pemberian imunisasi tetanus toxoid (TT).

b. Hubungan Sikap Dengan Pemberian Imunisasi TT

Menurut Notoatmodjo yang dikutip dalam (Yusriani \& Alwi, 2018), Sikap adalah suatu bentuk evaluasif atau reaksi perasaan, sikap seseorang terhadap suatu objek adalah perasaan mendukung atau memihak pada objek tersebut.Sikap sebagai efek positif atau efek negatif terhadap objek psikologis. Sikap sering diperoleh dari pengalaman sendiri atau orang lain. Sikap membuat seseorang untuk berbuat atau menjauhi sesuatu objek.

asumsi peneliti, bahwa ada hubungan antara sikap ibu hamil dengan pemberian imunisasi tetanus toxoid (TT). Karena sikap sebagai efek positif atau efek negatif terhadap objek psikologis. Sikap sering diperoleh dari pengalaman sendiri atau orang lain. Sehingga sikap membuat seseorang untuk berbuat atau menjauhi sesuatu objek.

\section{KESIMPULAN}

a. Umur ibu hamil yang menjadi responden mayoritas 20-30 tahun, pendidikan ibu hamil yang menjadi responden mayoritas SMA, pekerjaan ibu hamil yang menjadi responden mayoritas sebagai ibu rumah tangga dan jumlah kehamilan responden mayoritas kehamilan anak kedua.

b. Ibu yang memiliki pengetahuan baik sebanyak 31 orang $(58,5 \%)$ dan ibu hamil pengetahuan kurang baik sebanyak 22 orang $(41.5 \%)$. Ibu hamil yang memiliki pengetahuan baik yang mendapatkan imunisasi tetanus toxoid sebanyak 21 orang $(67.7 \%)$ dan yang tidak mendapatkan imunisasi tetanus toxoid sebanyak 10 orang (32.3\%). Ibu hamil yang memiliki pengetahuan kurang baik dan mendapatkan imunisasi tetanus toxoid sebanyak 5 orang $(27.8 \%)$ dan yang tidak mendapatkan imunisasi tetanus toxoid sebanyak 13 orang $(72.2 \%)$.

c. Ibu yang memiliki sikap baik sebanyak 35 orang (66.0\%) dan yang memiliki sikap buruk sebanyak 18 orang (34.0\%). Yang memiliki sikap baik dan mendapatkan imunisasi tetanus toxoid sebanyak 24 orang $(68.6 \%)$, yang tidak mendapatkan imunisasi tetanus toxoid sebanyak 11 orang $(31.4 \%)$. Ibu hamil yang memiliki sikap buruk dan mendapatkan imunisasi tetanus toxoid sebanyak 5 orang $(27.8 \%)$, yang tidak mendapatkan imunisasi tetanus toxoid sebanyak 13 orang $(72.2 \%)$.

d. Ada hubungan yang signifikan antara Pengetahuan Ibu Hamil Dengan Pemberian Imunisasi Di Puskesmas Sungai Panas Kota Batam Tahun 2020 dengan nilai $p$ value $=0,029<0,05$.

e. Ada hubungan yang signifikan antara Sikap Ibu Hamil Dengan Pemberian Imunisasi Di Puskesmas Sungai Panas Kota Batam Tahun 2020 dengan nilai $\mathrm{p}$ value $=0,008<0,05$.

\section{SARAN}

a. Bagi Institusi Pendidikan Universitas Batam

Dapat dijadikan sebagai bahan bacaan bagi mahasiswa Universitas Batam khususnya yang melakukan

penelitian tentang Hubungan Pengetahuan Dan Sikap Ibu Hamil Dengan Pemberian Imunisasi Tetanus Toxoid.

b. Bagi Petugas Kesehatan

Dapat memberikan masukan dan dapat digunakan sebagai bahan pertimbangan dalam meningkatkan hasil cakupan Imunisasi Tetanus Toksoid pada ibu hamil untuk menurunkan angka kesakitan dan kematian bayi akibat Tetanus Neonatorum dan meningkatkan keterampilan pengetahuan dan sikap tentang Imunisasi Tetanus Toksoid.

c. Bagi Ibu/Responden

Dapat memberikan informasi tentang Imunisasi Tetanus Toksoid sehingga masyarakat khusus nya ibu hamil mendapatkan pelayanan imunisasi Tetanus Toxoid secara lengkap. 


\section{E. DAFTAR PUSTAKA}

Dinas Kesehatan Kota Batam,(2018). Profil Kesehatan Kota Batam Tahun 2018 :Batam.

Dinas Kesehatan Provinsi Kepulauan Riau, 2019. Cakupan Imunisasi TT Pada Ibu Hamil Menurut Kabupaten / Kota Provinsi Kepulauan Riau Tahun 2018.

Donsu, Jenita Tine.(2017). Psikologi keperawatan.Yogyakarta : pustaka baru press.

Hadianti, D.N \& Mulyati Elis, dkk, (2015). Buku Ajar Imunisasi. Jakarta Selatan : Pusat Pendidikan dan Pelatihan Tenaga Kesehatan.

Kementerian Kesehatan Republik Indonesia, (2019). Cakupan Imunisasi Td2 Pada Ibu Hamil Tahun 2018 : Jakarta.

Masturoh Imas, dkk (2018). Metodologi Penelitian Kesehatan.Kementrian Kesehatan Republik Indonesia.

Monica, L, (2017). Hubungan Pengetahuan Dengan Sikap Ibu Hamil Dalam Melengkapi Imunisasi TT. Jurnal Ners dan Kebidanan, Volume 4, Nomor1, April 2017.

Notoatmodjo, S. (2014).PromosiKesehatan dan Perilaku Kesehatan. Edisi revisi.Jakarta:Rineka Cipta

Profil UPT Puskesmas Sungai Panas Kota Batam : 2019.

Rosmeri Br Bukit. Hubungan Pengetahuan Dan Sikap Ibu Hamil Terhadap Imunisasi Tetanus Toksoid. JOMIS (Journal Of Midwifery Science)Vol 2. No.2, Juli 2018.

Said Ali \& Budiati Indah dkk, (2016).Potret Awal Tujuan Pembangunan Berkelanjutan (Sustainable Development Goals) di Indonesia. Badan Pusat Statistik/Statistics Indonesia.

Setiyani Astuti, Sukesi \& Esyuananik,(2016). Asuhan KebidananNeonatus, Bayi, Balita danAnak Pra Sekolah. Jakarta : Kementerian Kesehatan Republik Indonesia.

Sulistyawati, A, (2011). Asuhan kebidanan Pada Masa Kehamilan. Jakarta: Salemba Medika.

Tyastuti Siti, (2016). Buku Asuhan Kebidanan Kehamilan. JakartaSelatan :Kementerian Kesehatan Republik Indonesia.Badan Pengembangan dan Pemberdayaan Sumber Daya Manusia.

Wijayanti Ida, (2013). Dalam Jurnal Hubungan Perilaku Dengan Kelengkapan Imunisasi Tetanus Toxoid Pada Ibu Hamil Di Wilayah Kerja Puskesmas Tagolu Kabupaten Poso. Jurnal Universitas Muhammadiyah Palu.

Yunica, J, (2015). Hubungan Pendidikan dan Sikap Ibu Hamil dengan Kelengkapan Imunisasi Tetanus Toxoid (TT) Pada Ibu Hamil Di Puskesmas Boom Baru Palembang.Jurnal Kesehatan Volume XI No. 1 Juni 2016.

Yusriani, dkk (2018). Promosi Kesehatan dan Pemberdayaan Masyarakat : Ponorogo. 